Article

\title{
Preparation of Cellulose Nanocrystal-Reinforced Physical Hydrogels for Actuator Application
}

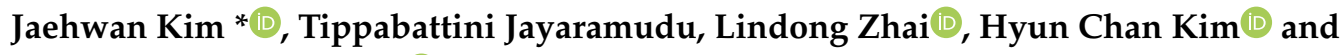 \\ Dickens Owino Agumba $\mathbb{D}$
}

Center for Nanocellulose Future Composites, Department of Mechanical Engineering, Inha University, 100 Inha-ro, Michuhol-ku, Incheon 22212, Korea; mr.jayaramudu@gmail.com (T.J.); duicaofei@naver.com (L.Z.); Kim_HyunChan@naver.com (H.C.K.); owinodickens@gmail.com (D.O.A.)

* Correspondence: jaehwan@inha.ac.kr; Tel.: +82-32-874-7325

Received: 21 September 2020; Accepted: 24 October 2020; Published: 26 October 2020

check for updates

\begin{abstract}
In the present investigation, we prepared cellulose nanocrystal (CNC)-reinforced polyvinyl alcohol-cellulose (PVA-Cell) physical hydrogels using a simple blending method for actuator application. The prepared hydrogels were characterized by Fourier transform infrared spectroscopy, X-ray diffraction, and the surface and cross-section were studied by scanning electron microscopy. CNCs were well dispersed in the PVA-Cell hydrogel. In the preparation process, surface hydroxyl groups of the CNC and PVA-Cell matrix hydroxyl groups were interacted to produce uniform dispersion of CNCs in the hydrogels. Swelling behavior and compression studies revealed that the increase of the CNCs reinforced the crosslinking. The actuation test of the prepared hydrogels showed that the displacement linearly increased with the voltage, and the immense output displacement was observed at low $\mathrm{CNC}$ concentration. The prepared hydrogels are applicable for soft robot actuators and active lens.
\end{abstract}

Keywords: soft actuators; physical hydrogels; cellulose nanocrystals; physical crosslinking

\section{Introduction}

In the last few decades, researchers have focused on synthesizing nanocomposite hydrogels for tissue engineering, drug delivery, antimicrobial, bioactive electrode coatings, actuators, and sensors [1-4]. Nanocomposite hydrogels are advantageous with softness, biocompatibility, multi-functionality, and adaptability. For making nanocomposite hydrogels, nanosized materials are reinforced with the materials. Generally, clay [5], silica, carbon nanotubes [6], gold [7], silver [2], and magnetic materials [8] are used as reinforcement materials that should be well dispersed in the hydrogel matrices. Beyond these reinforcement materials, cellulose nanocrystal (CNC) use gained much interest because of its renewable behavior $[9,10]$.

CNC is a rod/needle-shaped crystalline cellulose material, which is produced by acid hydrolysis of cellulose. Cellulose has both amorphous and crystalline regions in microfibrils. In acid hydrolysis, most of the amorphous regions of the cellulose microfibrils are removed by acid degradation and over the crystalline domains, which remain intact as they have a higher resistance to acid degradation $[11,12]$. The final acid hydrolysis residue gives a nanosized CNC suspension. Generally, CNC is less than $300 \mathrm{~nm}$ in length and $20 \mathrm{~nm}$ in width. This property depends on the source of cellulose raw materials [13]. CNCs can be used to improve the performance of a broad range of materials such as emulsions and foams, biomedical devices, electronics and sensors, high-viscosity fluids, and polymer composites. The raw materials are eco-friendly, with low-cost, and broadly available in nature. In addition, due to the mechanical properties of CNCs equal to metal, CNCs have potential applications. In composite areas, CNCs are used as reinforcing as fillers. For example, CNC-reinforced waterborne epoxy 
nanocomposites showed better tensile strength (60 MPa) than the neat epoxy matrix (40 MPa) [14]. Recently, new strategies are being used to reinforce hydrogels by using $\mathrm{CNC}$ to increase their properties to apply for drug delivery, tissue engineering, and biomedical applications [13-16]. For example, CNC-reinforced gelatin hydrogels were reported for controlled drug delivery applications using rice husks as a raw material [15]. CNC-reinforced alginate hydrogel beads were fabricated for methylene blue adsorption [17]. Recently, CNC-reinforced poly (diethylene glycol adipate) (PDEGA) nanocomposites were reported for reconfigurable microlens applications $[18,19]$. The addition of CNC in hydrogels improves its mechanical properties and enhances its dielectric properties to strengthen its actuation behavior without sacrificing its transparency [20]. However, the required electric field is still high.

To further extend the CNC reinforcement in hydrogels, this paper reports $\mathrm{CNC}$ reinforcement on polyvinyl alcohol (PVA)-cellulose (PVA-Cell) based hydrogels. In recent works, we reported PVA-Cell and PVA-CNC based physical hydrogels and investigated their electroactive behaviors [21,22]. The PVA-Cell hydrogel, an ionic gel, showed its maximum actuation strain, $1525 \mathrm{ppm}$, under a $0.25 \mathrm{~V} / \mathrm{mm}$ electric field. The actuation mechanism is a combination of electrostriction and ion migration effect. Similarly, the PVA-CNC hydrogel exhibited its maximum actuation strain, $2870 \mathrm{ppm}$ under $0.25 \mathrm{~V} / \mathrm{m}$ electric field. The PVA-CNC hydrogel was believed to be a non-ionic gel. Thus, the actuation mechanism might be an electrostatic effect. It is curious what would happen if these two hydrogels were mixed. Therefore, this paper investigated CNC reinforcement on PVA-Cell based physical hydrogels to further extend the CNC reinforcement in PVA-Cell hydrogel. In this research, the hydrophilic CNC-reinforced PVA-Cell (PCC) hydrogels were prepared via the physical blends method. Initially, the PVA and cellulose solution were mixed to form the PVA-Cell hydrogel matrix, and nanosized CNC was reinforced into the PVA-Cell matrix that will form a crosslinked hydrogel with a unique network. It results in PCC hydrogel. The prepared hydrogels were confirmed from Fourier transform infrared (FTIR) and X-ray diffraction (XRD) studies. Furthermore, the prepared PCC hydrogels' actuation behavior was tested by applying AC voltage in a hydrated state.

\section{Materials and Methods}

\subsection{Materials}

Cotton pulp (MVE, DP-4580) was supplied by Buckeye Technologies Co. Ltd. (Memphis, TN, USA) and polyvinyl alcohol (PVA $=89,000-98,000 \mathrm{~g} \mathrm{~mole}^{-1}, 99 \%$ hydrolyzed). Extra pure lithium chloride ( $\mathrm{LiCl}$, Daejung Chemical, Gyeonggi-Do, Korea) was carefully dried using an oven at $110^{\circ} \mathrm{C}$, $2 \mathrm{~h}$ before use. $\mathrm{N}, \mathrm{N}$-dimethylacetamide (DMAc), sulfuric acid $\left(\mathrm{H}_{2} \mathrm{SO}_{4}\right)$, and sodium hydroxide were purchased from Sigma-Aldrich, Gyeonggi-Do, Korea. Deionized (DI) water was used throughout the experiment.

\subsection{Preparation of Cellulose Nanocrystal}

In this study, CNC was prepared by the acid hydrolysis treatment [20,22], and here is a brief explanation. The pure cotton pulp (20.0 g) dispersed in $\mathrm{H}_{2} \mathrm{SO}_{4}(175 \mathrm{~mL}$ of $30 \%(v / v)$ aqueous) under mechanical stirring $(200 \mathrm{rpm}, 4 \mathrm{~h})$ at $60^{\circ} \mathrm{C}$. Before starting the acid hydrolysis process, an alkaline $(1 \mathrm{M} \mathrm{NaOH})$ treatment was carried out on the cotton cellulose to remove the non-cellulosic components and get the high yield of CNC prior. The hydrolysis left a suspension solution, which was further centrifuged with adding excess DI water to attain neutrality ( $\mathrm{pH}$ 7), followed by homogenization and dialysis. A certain amount of homogenized CNC was dispersed in $25 \mathrm{~mL}$ of DMAc and sonicated for $1 \mathrm{~h}$. Finally, $1 \% \mathrm{CNC}$ solution was obtained and stored at room temperature until to use.

\subsection{Preparation of Cellulose and PVA Solutions}

The cellulose solution was prepared according to our previous work, and here is a brief explanation [23]. The $1.5 \mathrm{~g}$ of pure cotton pulp was dispersed in $8.5 \mathrm{wt} . \% \mathrm{LiCl} / \mathrm{DMAc}$ solvent 
and stirred by using a magnetic stirrer at room temperature over 5 days. After completing this process, the solution was centrifuged to remove an undissolved portion of the cellulose, and, finally, $1.5 \mathrm{wt} . \%$ of the cellulose solution obtained. A similar approach was followed in the preparation of 3 wt.\% PVA.

\subsection{Preparation of CNC-Reinforced PVA-Cell Hydrogels}

Initially, a 1:1 ratio of PVA and cellulose solutions was mixed and stirred at room temperature $24 \mathrm{~h}$. After getting a homogeneous solution, a different amount of CNC (in mL) was added to the solution and stirred again. The well-dispersed CNC-reinforced solution was poured into a Petri dish and kept in an oven at $30^{\circ} \mathrm{C}$ for 3 days. After that, a transparent hydrogel was formed, then it was immersed in $500 \mathrm{~mL}$ beakers containing $250 \mathrm{~mL}$ of DI water. The water was repeatedly changed every $6 \mathrm{~h}$ for 5 days to remove $\mathrm{LiCl} / \mathrm{DMAc}$ and unreacted materials from the hydrogel. Table 1 shows the feed composition of the prepared PCC hydrogels.

Table 1. Feed composition and properties of CNC-reinforced PVA-Cell hydrogels.

\begin{tabular}{|c|c|c|c|c|c|}
\hline $\begin{array}{l}\text { Hydrogel } \\
\text { Ccode }\end{array}$ & $\begin{array}{c}\text { PVA Solution } \\
\text { (3 wt. } \% \text { ) } \\
\text { g }\end{array}$ & $\begin{array}{c}\text { Cellulose Solution } \\
(1.5 \text { wt. } \%) \\
\mathrm{g}\end{array}$ & $\begin{array}{c}1 \text { wt. } \% \text { CNC } \\
\mathrm{mL}\end{array}$ & $\begin{array}{l}\text { Swelling Ratio } \\
\qquad\left(\mathrm{S}_{\mathrm{g} / \mathrm{g}}\right)\end{array}$ & $\begin{array}{c}\text { Compressive } \\
\text { Modulus } \\
\mathbf{k P a}\end{array}$ \\
\hline PCC0 & 50 & 50 & - & 13.2 & 99.1 \\
\hline PCC1 & 50 & 50 & 1 & 14.8 & 65.8 \\
\hline PCC2 & 50 & 50 & 2 & 14.6 & 66.3 \\
\hline PCC3 & 50 & 50 & 3 & 13.4 & 88.5 \\
\hline
\end{tabular}

\section{Characterization}

FTIR spectrophotometer was used to study the chemical bondings of CNC-reinforced PVA-Cell hydrogels. Before the FTIR analysis, the samples were completely dried in a vacuum oven at $60{ }^{\circ} \mathrm{C}$ for $6 \mathrm{~h}$, and the spectra were recorded on the FTIR spectroscopy ranging from 400 to $4000 \mathrm{~cm}^{-1}$ (Bruker Optics, Billerica, MA, USA) by using the KBr disk pellet method with averaging 16 scans. XRD analysis was performed on the CNC, PCC0, and PCC3. An X-ray diffractometer (DMAX 2500, RIGAKU, Tokyo, Japan) was used to record the XRD graph using a $\mathrm{Cu} K \alpha$ radiation source $(\lambda=0.1542 \mathrm{~nm})$ at $40 \mathrm{kV}$ and $300 \mathrm{~mA}$. The running speed of the scan $2^{\circ}$ per min and the spectra of $2 \theta$ (Bragg angle) range from 5 to $45^{\circ}$. A scanning electron microscopy (SEM) was used to observe the morphology aspects of the prepared hydrogels. Before the SEM analysis, the samples were freeze-dried and coated with platinum. The images were taken using an SEM (S-4000, Hitachi, Tokyo, Japan) at an accelerating $15 \mathrm{kV}$ voltage. The PCC hydrogels' optical transparency was measured using a UV-visible spectrophotometer (HP8452A, Agilent, Santa Clara, CA, USA). For the measurement, the hydrogel specimen was cut into the desired shape, and the wavelength range was 400-800 nm. The compression stress test was conducted in a fully hydrated stage using a compression test machine with $10 \mathrm{~N}$ loadcell and a compressing speed of $0.0005 \mathrm{~mm} / \mathrm{s}$. The hydrogel samples $\left(2 \times 2 \times 0.4 \mathrm{~cm}^{3}\right)$ were kept in between two plates; the upper plate presses the specimen until it reaches the bottom fixed plate. The overall compression test was conducted at room temperature.

\section{Actuation Test}

The actuation test was carried out by using a computerized measurement system. The experimental setup was explained in our previous work, and here is a brief explanation [22,24]. Before conducting the test, the desired hydrogels $\left(10 \times 10 \times 4 \mathrm{~mm}^{3}\right)$ were equilibrated in DI water for $24 \mathrm{~h}$. After reaching the equilibration, the swollen hydrogels were kept in between two electrodes (polyimide tape attached indium tin oxide (ITO) glass), and then an electric field was applied between the electrodes. A high voltage amplifier (20/20, Trek, Waterloo, WI, USA) was connected to a function generator (33220A, Agilent, Santa Clara, CA, USA) for applying a high voltage to the electrode. The experiment was conducted in an environmental chamber, and the chamber temperature and humidity were maintained constant $\left(25^{\circ} \mathrm{C}, 95 \% \mathrm{RH}\right)$ throughout the experiment. Displacement of the hydrogels was measured 
using a laser displacement sensor (LK-G85, Keyence, Tokyo, Japan) and a data acquisition system (Pulse, B \& K, Nærum, Denmark).

\section{Results and Discussion}

The PCC hydrogels were prepared by a physical blending method. Figure 1 shows the formation of the hydrogels. For the hydrogel preparation, a 1:1 wt. $\%$ ratio of 3\% PVA and $1.5 \%$ cellulose solutions were mixed and stirred until getting the homogeneous solution. A different amount of CNC solution was added to the PVA-cellulose solution, followed by stirring. The homogeneous solution was poured into a Petri dish and kept in an oven at $30^{\circ} \mathrm{C}$ for 3 days. During this step, intermolecular hydrogen bonds can occur because all the materials have hydroxyl groups.

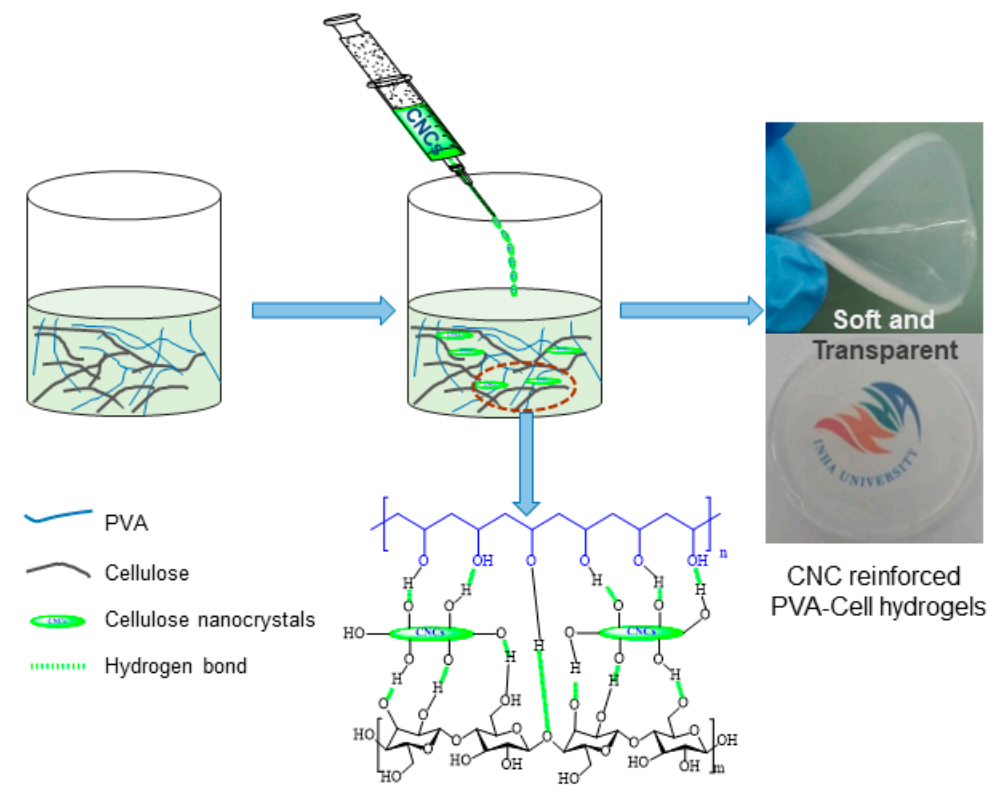

Figure 1. Preparation of CNC-reinforced PVA-Cell hydrogels.

\subsection{FTIR Analysis}

The formation of the CNC-reinforced PVA-Cell hydrogels was confirmed from the FTIR spectra. Figure 2a illustrates the CNC, PVA-Cell (PCC0) hydrogel, and PCC3 hydrogel. The broad absorption peak at $3425 \mathrm{~cm}^{-1}$ corresponds to the $-\mathrm{OH}$ stretching vibration of the pure PVA. The characteristic peaks at $1070 \mathrm{~cm}^{-1}$ and $2922 \mathrm{~cm}^{-1}$ are related to stretching vibrations of the C-O and C-H [25]. The CNC shows a broad peak at $3366 \mathrm{~cm}^{-1}$, which is related to the $\mathrm{O}-\mathrm{H}$ stretching vibration. The $\mathrm{C}-\mathrm{H}$ stretching vibration peak is shown at $2901 \mathrm{~cm}^{-1}$. The peak at $1628 \mathrm{~cm}^{-1}$ is related to an acetyl group $(\mathrm{C}=\mathrm{O})$, which is induced from the preparation of PVA. A bending vibration related to $\mathrm{CH} 2$ groups is observed in the region of 1430-1446 cm $\mathrm{cm}^{-1}$. The prominent peak observed at $1060 \mathrm{~cm}^{-1}$ is associated with the C-O-C pyranose ring skeletal vibrations [26]. In the case of PCC3 hydrogels, all of the above characteristic peaks are shown, and there is no difference when compared to the PVA-Cell hydrogel. It means that the reinforcement of CNC doesn't affect the PVA-Cell hydrogels' chemical structure. 


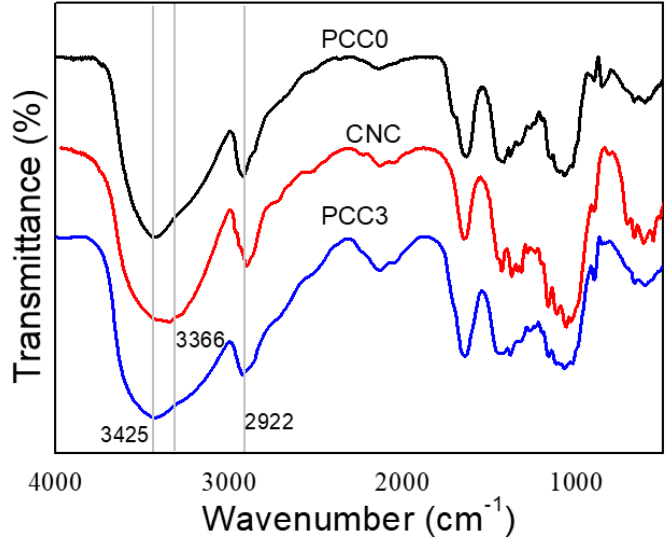

(a)

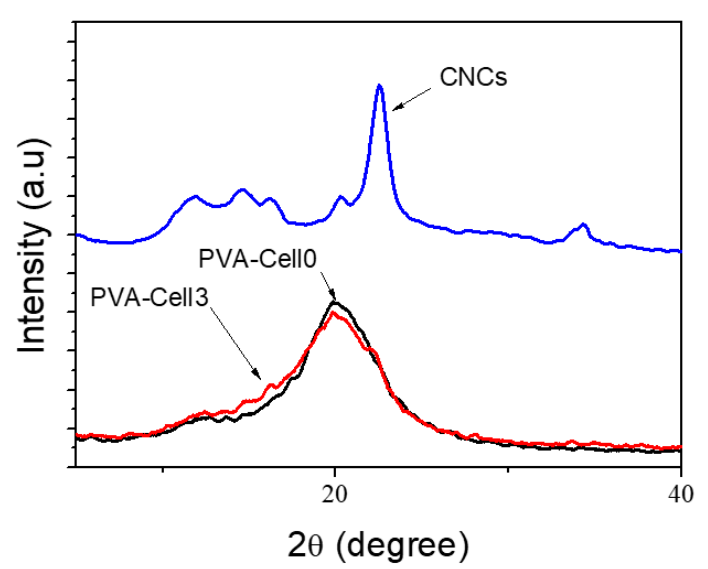

(b)

Figure 2. Spectral analysis of CNC, PVA-Cell (PCC0), and PCC3 hydrogels: (a) FTIR spectra; (b) X-ray diffraction.

\subsection{XRD Studies}

The XRD curves of CNC, PVA-Cell (PCC0) hydrogel, and PCC3 hydrogel are shown in Figure 2b. CNC exhibits four well-defined diffraction peaks at $2 \theta=14.6,16.2,22.5$, and $34.4^{\circ}$, which are supposed to represent the typical cellulose-I structure [27]. The PVA-Cell hydrogel shows two peaks at $2 \theta=20.0^{\circ}$ and $12.3^{\circ}$, between the PVA and cellulose peaks explained in the previous work [21], which might be due to the intermolecular bond formation between hydroxyl groups of PVA and cellulose. In the case of PCC3 hydrogel, similar peaks of the PVA-Cell hydrogel are shown but less intensity of these peaks in the PCC3 hydrogel. This is because CNCs are well dispersed in the PVA-Cell hydrogel to form intermolecular hydrogen bonds uniformly between the reactant materials. An additional peak at $22.5^{\circ}$ also corresponds to the distribution of CNC in the PVA-Cell hydrogel. An SEM analysis was taken to confirm the uniform dispersion of CNCs.

\subsection{Surface Morphology}

The SEM cross-sectional images of the PVA-Cell and PCC3 hydrogels are presented in Figure 3. The SEM observation reveals that both hydrogels show a similar structure: no changes induced by CNC into PVA-Cell hydrogels. Figure 3a shows that the PCC0 hydrogel possesses a rough layer by layer structure, and this layer by layer structure was condensed by the addition of $\mathrm{CNC}$, as shown in Figure $3 \mathrm{~b}$. It indicates that $\mathrm{CNC}$ are well dispersed in the hydrogel matrix through intermolecular hydrogen bonds. This result was confirmed by the previous FTIR and XRD studies.

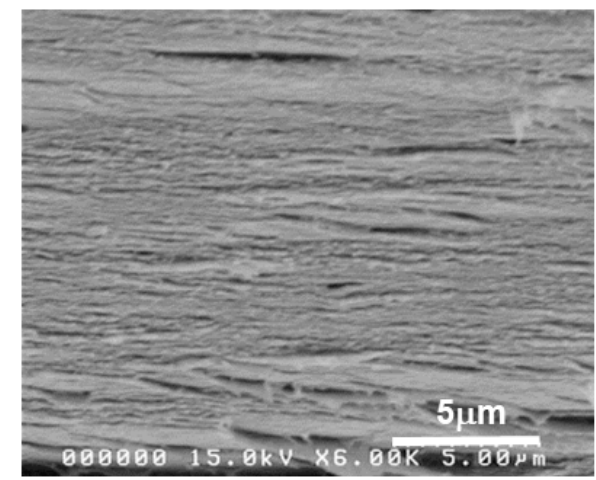

(a)

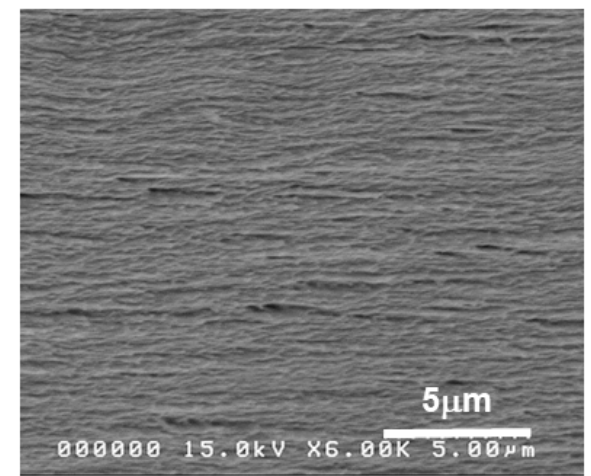

(b)

Figure 3. Cross-sectional SEM images: (a) PCC0 hydrogel; (b) PCC3 hydrogel. 


\subsection{Optical Transparency}

Optical transparency of the PCC hydrogels was measured using UV-vis spectroscopy in a fully hydrated state, and the results are shown in Figure 4. The hydrogel thickness was $2 \pm 0.2 \mathrm{~mm}$. The transparency decreases as the CNC concentration increased. It depends on the composition of CNC reinforcement in the hydrogel matrix. It was reported that a higher concentration of $\mathrm{CNC}$ decreases transparency $[18,22]$.

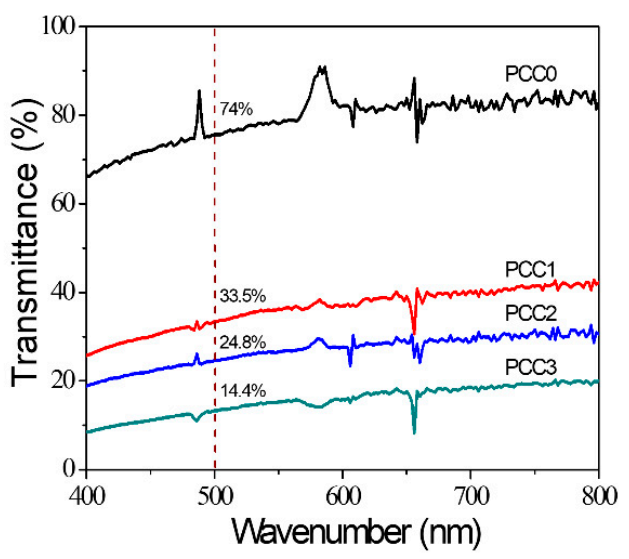

Figure 4. Optical transparency of PCC hydrogels.

\subsection{Mechanical Properties and Swelling Behaviors}

Mechanical properties of the prepared hydrogels were measured using the compression test under a fully hydrated stage, and results are shown in Figure 5a. The last column of Table 1 shows the results. All prepared hydrogels show almost linear stress-strain curves at a low strain range, below $20 \%$. The compression modulus of the PCC0 shows $99.1 \mathrm{kPa}$, and this compression modulus value decreases by the addition of CNC. For example, the compression modulus of PCC1 hydrogel is reduced to $65.8 \mathrm{kPa}$. When CNC concentration is increased to $3 \mathrm{~mL}$ (PCC3), the compression modulus is increased to $88.5 \mathrm{kPa}$, associated with the expanded crosslinking network. The overall compression modulus of PCC hydrogels is shown to be lower than the PCC0 hydrogel, and the order of the CNC-reinforced PVA-Cell hydrogels follows in this manner: PCC $1<$ PCC 2 PCC $3<$ PCC 0 . Note that these values are larger than the PVA-CNC hydrogels (7-40 kPa) [22] and a bit smaller than the PVA-Cell hydrogels (90-170 kPa) [21]. This compression modulus behavior was further confirmed by swelling behavior.

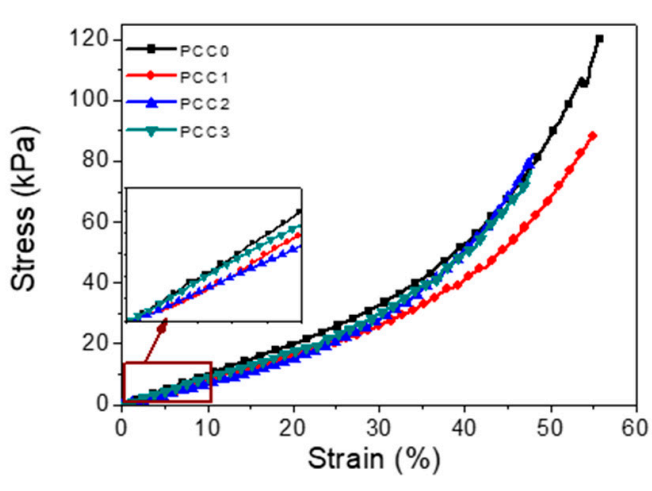

(a)

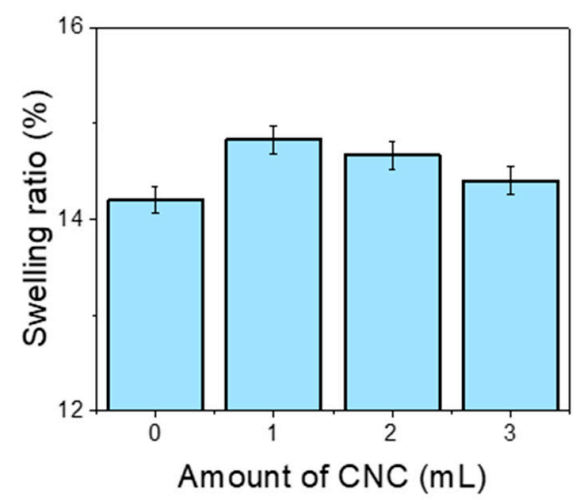

(b)

Figure 5. Result for mechanical and swelling tests of PCC hydrogel: (a) stress-strain curves and (b) swelling ratio.

The CNC-reinforced PVA-Cell hydrogels' swelling test was carried out using the analytical method [27]. Pre-weighed air-dried hydrogels were immersed in DI water at room temperature until 
their $(48 \mathrm{~h})$ swelling was saturated to measure the prepared hydrogels' swelling ratio. The swollen hydrogels were weighed after removing excess water using a filter paper. The equilibrium swelling ratio was calculated using the following equitation:

$$
\text { Swelling ratio } \mathrm{S}_{\mathrm{g} / \mathrm{g}}=\left(\mathrm{W}_{\mathrm{s}}-\mathrm{W}_{\mathrm{o}}\right) / \mathrm{W}_{\mathrm{o}}
$$

where $\mathrm{W}_{\mathrm{o}}$ and $\mathrm{W}_{\mathrm{s}}$ correspond to the weight of dry and swollen states of the hydrogels, respectively. The swelling behavior plays a vital role in hydrogel technology. It entirely depends on the crosslinking structure. Therefore, the swelling behavior is quite the opposite of crosslinking, which means that as the crosslinking increases, the swelling behavior decreases.

The swelling experiment was carried out at room temperature and repeated three times to reduce errors. Figure $5 \mathbf{b}$ shows the swelling behavior of the PCC hydrogels. Table 1 also shows the result. Swelling ratios of PCC hydrogels were larger (14-15) than the PVA-CNC hydrogels (2.3-2.5) [22] and comparable with the PVA-Cell hydrogels (12-14) [21]. When the CNC is added, the molecular entanglement between cellulose and PVA is weakened, which leads to water molecules get trapped in the available free volumes of the hydrogels. It resulted in improved swelling ratios of the PCC1 hydrogel. However, further addition of CNC in the hydrogel decreases the functional groups' availability, which interacts with water molecules, reducing the hydrogels' swelling ratio [28-30].

\subsection{Actuation Test}

In the current research, the active behavior of the prepared PCC hydrogels was measured as a function of displacement in the presence of an electric field. The displacement performance was investigated in terms of frequency and voltage change. Figure 6 shows the displacement outputs of the prepared PCC hydrogels at a constant frequency of $0.1 \mathrm{~Hz}$ with different voltages (Figure 6a) and a constant voltage with different frequencies (Figure $6 \mathrm{~b}$ ). The displacement outputs linearly increase with increasing the voltage in all the samples. The maximum displacement values of PCC0, PCC1, PCC2, and PCC3 hydrogels are 5.51, 6.74, 5.85, and $3.33 \mu \mathrm{m}$, respectively, at $1.0 \mathrm{kV}$. The maximum displacement of PCC1 corresponds to the $1690 \mathrm{ppm}$ strain under $0.25 \mathrm{~V} / \mathrm{m}$. Note that, from the maximum displacement and compression modulus of PCC1, the force output can be $111.2 \mathrm{~N} / \mathrm{m}$, which corresponds to $1.1 \mathrm{~N}$, the net force output. However, the net force output of PVA-CNC (PCC3) was $0.2 \mathrm{~N}$, and the PVA-Cell was $2.6 \mathrm{~N}$. Figure $6 \mathrm{~b}$ shows the frequency-dependent displacement values at constant voltage $(1.0 \mathrm{kV})$. The displacement output mostly decreases with increasing the frequency.

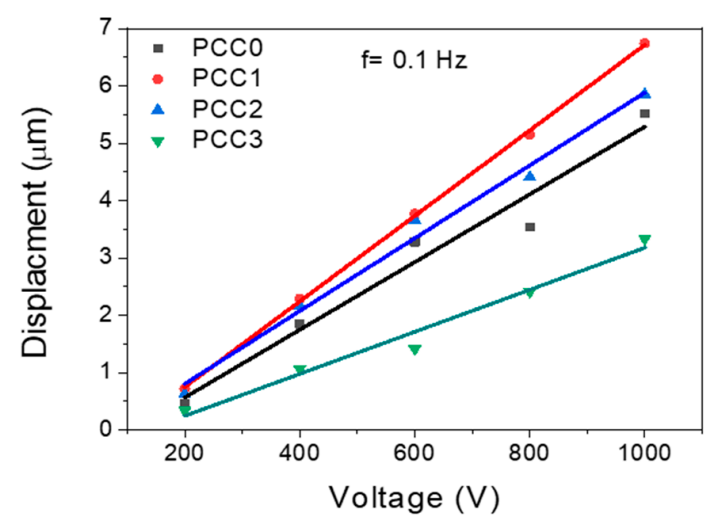

(a)

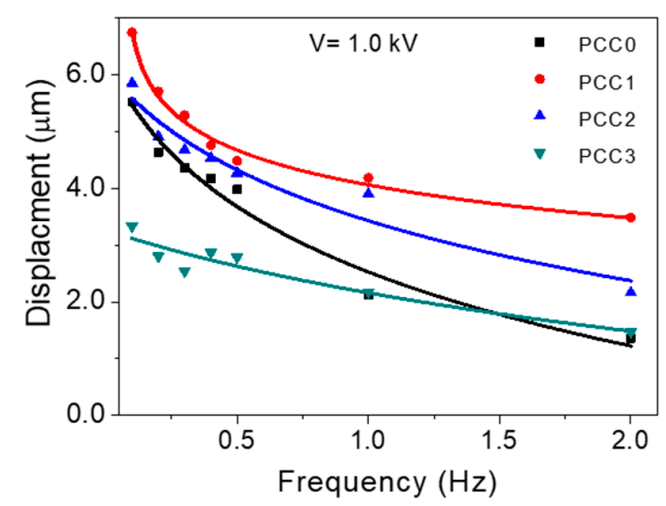

(b)

Figure 6. Actuation test results of PCC hydrogels: (a) voltage-dependent displacement output at $0.1 \mathrm{~Hz}$ and $(\mathbf{b})$ frequency-dependent displacement output at $1.0 \mathrm{kV}$.

The trend seems to have manifested according to the CNC properties such as nanosize, $\mathrm{pH}$ sensitivity, and dielectric $[9,20]$. These results indicate that the $1 \%$ concentration of CNC exhibits the best actuation output. PVA-Cell is an ionic hydrogel [21]; meanwhile, PVA-CNC is a non-ionic one [22]. 
Since PCC hydrogel is a combination of PVA-Cell and PVA-CNC, its actuation mechanism is associated with the combination of electrostatic effect and ion migration effect. The actuation performance of PCC hydrogels is associated with its dielectric behavior as well as its softness. The dielectric behavior can be enhanced by adding CNC because of the interfacial polarization of CNC and PVA. However, it can adversely stiffen the hydrogel, which hinders deformation under actuation. Thus, there is an optimum CNC content that maximizes the actuation performance. We believe that PCC1 is an optimum condition for actuation. The PCC1 showed the smallest compression modulus and the highest swelling behavior. Low compression modulus and high swelling ratio are beneficial for improving the actuation displacement.

\section{Conclusions}

Successfully, we prepared hydrophilic CNC-reinforced PVA-Cell hydrogels via a physical blending method. The chemical formation and physical structure of the prepared hydrogels were confirmed using FTIR and XRD. SEM cross-sectional images revealed that CNCs were well dispersed in the PVA-Cell hydrogel matrix. Optical transparency decreased upon increasing the $\mathrm{CNC}$ concentration. The CNC concentration affected the swelling behavior and compression modulus: the swelling behavior initially increased by expanding the $\mathrm{CNC}$ concentration and decreased.

Meanwhile, the compression modulus initially decreased and rose again. The swelling behavior was inversely proportional to the compression modulus. The actuation test of the hydrogels revealed that the lower concentration of $\mathrm{CNC}$ showed higher displacement output. The prepared hydrogels can be applied to soft robot actuators such as an active lens.

Author Contributions: Conceptualization, T.J. and J.K.; methodology, T.J.; validation, H.C.K. and D.O.A.; investigation, L.Z.; resources, T.J.; writing-original draft preparation, T.J.; writing-review and editing, J.K.; visualization, D.O.A.; supervision, J.K.; funding acquisition, J.K. All authors have read and agreed to the published version of the manuscript.

Funding: This research was funded by Inha University Research Grant.

Conflicts of Interest: The authors declare no conflict of interest.

\section{References}

1. Reddy, N.N.; Mohan, Y.M.; Varaprasad, K.; Ravindra, S.; Joy, P.A.; Raju, K.M. Magnetic and electric responsive hydrogel-magnetic nanocomposites for drug-delivery application. J. Appl. Polym. Sci. 2011, 122, 1364-1375. [CrossRef]

2. Kim, J.; Kim, J.W.; Kim, H.C.; Zhai, L.; Ko, H.-U. Review of Soft Actuator Materials. Int. J. Precis. Eng. Manuf. 2019, 20, 2221-2241. [CrossRef]

3. Belviso, B.D.; Caliandro, R.; Salehi, S.M.; Di Profio, G.; Caliandro, R. Protein Crystallization in Ionic-Liquid Hydrogel Composite Membranes. Crystals 2019, 9, 253. [CrossRef]

4. Kruusamäe, K.; Punning, A.; Aabloo, A.; Asaka, K. Self-Sensing Ionic Polymer Actuators: A Review. Actuators 2015, 4, 17-38. [CrossRef]

5. Bounabi, L.; Mokhnachi, N.B.; Haddadine, N.; Ouazib, F.; Barille, R. Development of poly(2-hydroxyethyl methacrylate)/clay composites as drug delivery systems of paracetamol. J. Drug Deliv. Sci. Technol. 2016, 33, 3358-3365. [CrossRef]

6. Cancian, G.; Tozzi, G.; Hussain, A.; De Mori, A.; Roldo, M. Carbon nanotubes play an important role in the spatial arrangement of calcium deposits in hydrogels for bone regeneration. J. Mater. Sci. Mater. Med. 2016, 27, 126. [CrossRef] [PubMed]

7. Jayaramudu, T.; Raghavendra, G.M.; Varaprasad, K.; Sadiku, R.; Raju, K.M. Development of novel biodegradable Au nanocomposite hydrogels based on wheat: For inactivation of bacteria. Carbohydr. Polym. 2013, 92, 2193-2200. [CrossRef] [PubMed]

8. Jayaramudu, T.; Raghavendra, G.M.; Varaprasad, K.; Raju, K.M.; Sadiku, R.; Kim, J. 5-Fluorouracil encapsulated magnetic nanohydrogels for drug-delivery applications. J. Appl. Polym. Sci. 2016, 133, 1-10. [CrossRef] 
9. Kim, J.-H.; Shim, B.S.; Kim, H.S.; Lee, Y.-J.; Min, S.-K.; Jang, D.; Abas, Z.; Kim, J. Review of nanocellulose for sustainable future materials. Int. J. Precis. Eng. Manuf. Green Technol. 2015, 2, 197-213. [CrossRef]

10. Ruiz-Palomero, C.; Soriano, M.L.; Valcárcel, M. Nanocellulose as analyte and analytical tool: Opportunities and challenges. TrAC Trends Anal. Chem. 2017, 87, 1-18. [CrossRef]

11. Sun, B.; Zhang, M.; Hou, Q.; Liu, R.; Wu, T.; Si, C. Further characterization of cellulose nanocrystal (CNC) preparation from sulfuric acid hydrolysis of cotton fibers. Cellulose 2016, 23, 439-450. [CrossRef]

12. Abitbol, T.; Kloser, E.; Gray, D.G. Estimation of the surface sulfur content of cellulose nanocrystals prepared by sulfuric acid hydrolysis. Cellulose 2013, 20, 785-794. [CrossRef]

13. Vanderfleet, O.M.; Cranston, E.D. Production routes to tailor the performance of cellulose nanocrystals. Nature Rev. Mater. 2020. [CrossRef]

14. Xu, S.; Girouard, N.; Schueneman, G.; Shofner, M.L.; Meredith, J.C. Mechanical and thermal properties of waterborne epoxy composites containing cellulose nanocrystals. Polymers 2013, 54, 6589-6598. [CrossRef]

15. Ooi, S.Y.; Ahmad, I.; Amin, M.C.I.M. Cellulose nanocrystals extracted from rice husks as a reinforcing material in gelatin hydrogels for use in controlled drug delivery systems. Ind. Crops Prod. 2016, 93, 227-234. [CrossRef]

16. Yang, J.; Zhang, X.-M.; Xu, F. Design of cellulose nanocrystals template-assisted composite hydrogels: Insights from static to dynamic alignment. Macromolecules 2015, 48, 1231-1239. [CrossRef]

17. Mohammed, N.; Grishkewich, N.; Waeijen, H.A.; Berry, R.M.; Tam, K.C. Continuous flow adsorption of methylene blue by cellulose nanocrystal-alginate hydrogel beads in fixed bed columns. Carbohydr. Polym. 2016, 136, 1194-1202. [CrossRef] [PubMed]

18. Sadasivuni, K.K.; Ponnamma, D.; Ko, H.-U.; Zhai, L.; Kim, H.-C.; Kim, J. Electroactive and optically adaptive bionanocomposite for reconfigurable microlens. J. Phys. Chem. B 2016, 120, 4699-4705. [CrossRef] [PubMed]

19. Ko, H.-U.; Kim, H.C.; Kim, J.W.; Zhai, L.; Jayaramudu, T.; Kim, J. Fabrication and characterization of cellulose nanocrystal based transparent electroactive polyurethane. Smart Mater. Struct. 2017, 26, 085012. [CrossRef]

20. Gao, X.; Sasasivuni, K.K.; Kim, H.-C.; Min, S.-K.; Kim, J. Designing pH-responsive and dielectric hydrogels from cellulose nanocrystals. J. Chem. Sci. 2015, 127, 1119-1125. [CrossRef]

21. Jayaramudu, T.; Ko, H.-U.; Zhai, L.; Li, Y.; Kim, J. Preparation and characterization of hydrogels from polyvinyl alcohol and cellulose and their electroactive behavior. Soft Mater. 2017, 15, 64-72. [CrossRef]

22. Jayaramudu, T.; Ko, H.-U.; Kim, H.C.; Kim, J.W.; Muthoka, R.M.; Kim, J. Electroactive hydrogels made with polyvinyl alcohol/cellulose nanocrystals. Materials 2018, 11, 1615. [CrossRef] [PubMed]

23. Yadav, M.; Mun, S.; Hyun, J.; Kim, J. Synthesis and characterization of iron oxide/cellulose nanocomposite film. Int. J. Biol. Macromol. 2015, 74, 142-149. [CrossRef] [PubMed]

24. Jayaramudu, T.; Li, Y.; Ko, H.-U.; Shishir, I.R.; Kim, J. Poly(acrylic acid)-poly(vinyl alcohol) hydrogels for reconfigurable lens actuators. Int. J. Precis. Eng. Manuf. Green Technol. 2016, 3, 375-379. [CrossRef]

25. Raghunathan, S.P.; Narayanan, S.; Poulose, A.C.; Joseph, R. Flexible regenerated cellulose/polypyrrole composite films with enhanced dielectric properties. Carbohydr. Polym. 2016, 157, 1024-1032. [CrossRef] [PubMed]

26. George, J.; Sabapathi, S.N. Cellulose nanocrystals: Synthesis.; functional properties and applications. Nanotechnol. Sci. Appl. 2015, 8, 45-54. [CrossRef]

27. Murthy, P.S.K.; Murali Mohan, Y.; Varaprasad, K.; Sreedhar, B.; Mohana Raju, K. First successful design of semi-IPN hydrogel-silver nanocomposites: A facile approach for antibacterial application. J. Colloid Interface Sci. 2008, 318, 217-224. [CrossRef]

28. Qi, X.; Hu, X.; Wei, W.; Yu, H.; Li, J.; Zhang, J.; Dong, W. Investigation of Salecan/poly (vinyl alcohol) hydrogels prepared by freeze/thaw method. Carbohydr. Polym. 2015, 118, 60-69. [CrossRef]

29. Tanpichai, S.; Oksman, K. Cross-linked nanocomposite hydrogels based on cellulose nanocrystals and PVA: Mechanical properties and creep recovery. Compos. Part A Appl. Sci. Manuf. 2016, 88, 226-233. [CrossRef]

30. Shin, W.H.; Min, M.S.; Lee, T.H.; Jho, J.Y.; Rhee, K. Computational simulation of spirally coiled deformation of a Bi-Layered hydrogel strip induced by swelling. Int. J. Precis. Eng. Manuf. 2015, 16, 409-412. [CrossRef]

Publisher's Note: MDPI stays neutral with regard to jurisdictional claims in published maps and institutional affiliations. 